\title{
VERSOS A MEDIANOCHE EN EL CAFÉ VARELA
}

\author{
Juan A. Ríos Carratalá \\ Universidad de Alicante
}

\author{
«Minglanilla fue el que dio lugar al incidente primero de la noche; antes de empezar a \\ recitar cometió el error de saludar: \\ -Señoras y señores... \\ Y un chusco saltó: \\ -¡Eso es plagio!» (Azcona, 1958, 89)
}

Subir a la tarima y recitar poemas en el Café Varela de la madrileña calle Preciados suponía un desafío no apto para pusilánimes. Según Manuel Alcántara, aquel local «era como un saloon del Oeste» (Ordóñez, 2007, 40). Si el poeta conseguía atraer la atención del respetable con sus versos, le dejaban seguir hasta el final, a pesar de alguna interrupción fruto de un ambiente algo bullanguero. Lo peligroso comenzaba cuando el vate se eternizaba con sus penas líricas, se mostraba apocado o no convencía al público. El embarazoso silencio podía ser roto por algún comentario inoportuno de los espectadores. Peor todavía era que el verbo demasiado florido y abundante fuera utilizado en las presentaciones. Lo pudo comprobar el retórico Somorrostro que, con voz campanuda, moviendo mucho los brazos, una noche «comenzó a explicar lo maravilloso que resultaba estar allí todos reunidos, unidos, confundidos, apretados, estrechados, hermanados y abrazados en torno a la Poesía». La impaciencia se asomaba en algún semblante, pero la situación empeoró cuando el rapsoda aseguró que «era la Poesía lo más hermoso, bello, importante, digno, trascendente, sublime, divino y humano que existía en el mundo». El impulso declamatorio le impidió calcular la respuesta de los agotados espectadores y, justo cuando iba a considerar «el mérito, el sacrificio, la dedicación, el entusiasmo, la 
honradez y la nobleza que hacían falta para ser poeta», cometió el error de preguntar:

- ¿Quién más noble que el poeta?

La respuesta sonó como un estampido:

-¡El Duque de Alba, sin ir más lejos, imbécil!» (Azcona, 1958, 53).

En estos casos, y a pesar del sofoco que alteró los ánimos de la esposa del ridiculizado Somorrostro, convenía no enfrentarse a «los resentidos» o «los de las barbas» con apariencias de existencialistas. Era preferible desistir para evitar la humillación de ser bajado de la tarima a gorrazos ${ }^{1}$. Resignado ante la incomprensión general, al vate no le quedaba más remedio que, con dignidad, retirarse a la espera de una nueva oportunidad en cualquiera de los otros cafés madrileños donde se celebraban recitales que reunían a los personajes más variopintos. ${ }^{2}$

Apenas había comenzado la década de los cincuenta y cada viernes, a las once y treinta de la noche, se agolpaban en el Varela «hasta doscientos poetas», según un impertérrito optimista al que escuchó en una ocasión Rafael Azcona. Muchos no serían nunca elegidos por las musas, pero todos, al menos, estaban dispuestos a participar en los pronto famosos Versos a medianoche. Estos recitales fueron concebidos en 1946 por Eduardo Alonso, un encantador y singular industrial de la venta a plazos que había descubierto su vocación lírica en fechas tardías. La vivía con la intensidad de quien suponía haber perdido el tiempo en otros menesteres más vulgares que, sin embargo, le permitían una generosidad agradecida por sus menesterosos amigos de la bohemia y las letras. Arriaga, así se le denomina en la

1. Rafael Azcona me comenta en un email del 8-IX-07 que nunca se llegó a las manos en estas ocasiones. Más bien hubo motivos para la sonrisa: «Lo que sí me viene a la memoria es la indignación de un sonetista -comandante jubilado del ejército; se me escapa ahora su apellido-cuando un cabroncete le fue con el cuento de que alguien andaba diciendo que los sonetos los «sacaba» de Las mil mejores poesías de la lengua castellana, la entonces muy leída antología de Bergua, y que tras el «alguien» se escondía el alma de Dios de Eduardo Alonso. «¿Plagiario, yo? -bramó el bizarro militar. Y levantándose de su mesa cargó hacia la de Eduardo y le dio una bofetada (a Eduardo, no a la mesa). -Es verano y no llevo guantes. Pero quede claro que le espero a usted en el campo del honor. El arma la dejo a su elección». Nos reímos mucho, nombrando padrinos y todo eso».

2. Manuel Alcántara recuerda que «En muchos cafés de entonces había aquellas tarimas, donde los domingos tocaban violinistas, y sus dueños pronto siguieron la brecha abierta por el Varela y comenzaron a ofrecer veladas de poesía una vez a la semana, de modo que si te abucheaban en el Varela, que estaba en Preciados esquina a Veneras, cruzabas muy dignamente la Puerta del Sol y te ibas a probar fortuna al Lisboa, en el arranque de Arenal, que también tenía tarima, de modo que en Madrid acabó habiendo más poetas que ventanas» (Ordóñez, 2007, 40). Puede observarse una antológica escena de café con mujeres violinistas en El pisito (1958), de Marco Ferreri y guión de Rafael Azcona. 
citada novela de Rafael Azcona, se consideraba un poeta «de tarde» porque escribía a la hora del café, utilizando los recibos de las consumiciones. Eran, según Manuel Alcántara, «poemas muy cortos, de tres o seis versos, como haikus castizos, justo lo que le cabía en cada papelito» (Ordóñez, 2007, 39). Gracias a la iniciativa del desmesurado cineasta Manuel Mur Oti y el apoyo del también singular César González Ruano, Eduardo Alonso los recopiló y editó en un volumen titulado Tickets de café (1948). No ha dejado huellas en los anales de la poesía española de la época. Tampoco los recitales que con tanto poder de convocatoria organizó durante varios años.

La citada obra de Eduardo Alonso es una de las pocas muestras que nos han llegado de la obra de aquellos poetas de café con tarima, a menudo jóvenes y venidos de provincias «en pos de una gloria esquiva, quizás inexistente» (Frugone, 1987, 32). Fueron los protagonistas de un movimiento pronto extendido por diversos locales madrileños: «Juvencia, en el Suizo; Noches y versos, en aquel café de Lavapiés; Nosotros, en el Bilbao...» (Azcona, 1958, 67) ${ }^{3}$. Allí les acogieron sin espíritu de mecenazgo por parte de los propietarios. El motivo de su generosidad era tan prosaico como la recaudación de la caja: aquellos recitales donde se agolpaban tipos singulares y variopintas creaciones suponían un aliciente para la clientela deseosa de pasar una noche confortable y barata fuera de las gélidas casas de la época ${ }^{4}$. Suponemos que muchas de las poesías leídas ni siquiera habrían obtenido un accésit en unos juegos florales provincianos donde la gloria era una flor natural. Salvo los autores, nadie estaría dispuesto a asegurar que fueran dignas de los honores de la imprenta. A pesar, incluso, del entusiasmo de personajes como el incansable Arriaga, que se desvivía para organizar los recitales con la confianza de que su obra trascendería:

¡Hasta en París se habla ya de Versos sabáticos! El movimiento es arrollador. ¿Cuándo, cuándo se había visto un resurgir de la Poesía como el que estamos viendo ahora? ¡No sólo se celebran recitales en los cafés de Madrid, sino que también nos imitan en provincias!» (ibid., 133).

3. Manuel Alcántara: «Ahora ya no hay bohemios, es una especie extinguida: poetas menesterosos que recitaban en los cafés y dormían forrados de papel de diario en los bancos de la plaza de Oriente. La lectura de versos de diario en los cafés se puso de moda como un último coletazo del romanticismo decimonónico» (Ordóñez, 2007, 39).

4. Rafael Azcona ha recordado en repetidas ocasiones el frío de las casas madrileñas de la época como una de las justificaciones de las tertulias en los cafés, menos creativas en su recuerdo que en la nostalgia de otros autores: «Aparte de que las tertulias -hablo de las tertulias en general- existían porque en las casas hacía un frío glacial y la gente iba a los cafés en busca del calor animal, durante noches y noches allí no se decían más que lugares comunes, cosa lógica [...] Pero, claro, se recuerda y se alaba lo que se escoge a lo largo de un montón de horas de charla» (Riambau y Torreiro, 2000, 17). 
Tal vez París quedara demasiado lejos, pero algo de razón había en la afirmación del vate vespertino. Resulta fácil encontrar en los cafés provincianos de la época algunos fenómenos similares. Sus protagonistas solían ser poetas sólo recordados en publicaciones locales casi nunca consultadas. Un destino gris como el tono de la época reflejada en Calle Mayor (1956), de Juan Antonio Bardem, cuyo Don Miguel, acomodado en la solitaria biblioteca del casino, enumera los hitos culturales de su ciudad provinciana ante Federico, el visitante con ansia de conocer. Le habla de «La tertulia en el Café Nuevo alrededor de nuestro poeta local... ¿Le conoce? Todos los años gana la flor natural» (Bardem, 1993, 8). Las acumularía en una vitrina del salón familiar. Su contemplación en compañía de las visitas le reconfortaría como un símbolo más de una realidad local con voluntad de permanencia, pero no deja de ser un inútil empeño convertido en rutina cuyos rasgos fundamentales Camilo José Cela sintetizó en el apunte titulado Unos juegos florales: tristeza, pobreza, ensoñación, cursilería... (1965, 184).

No obstante, los aspirantes a la gloria literaria y partícipes de los Versos a medianoche contaron con la fortuna de que uno de sus contertulios, Rafael Azcona, se convirtiera en un lúcido observador que trasladó el ambiente bohemio del Varela y otros cafés a su novela Los ilusos ${ }^{5}$. A pesar de la nula atención prestada por una crítica literaria que suele menospreciar los títulos publicados en las colecciones de humor, la citada obra azconiana ha quedado como un divertido e interesante testimonio de una realidad condenada a lo efímero: las poesías y los poetas de unas veladas cuya singularidad nos ayuda a comprender mejor aquella época de una bohemia alicorta y disparatada.

Rafael Azcona (1926) llegó a Madrid en 1951 procedente de Logroño, donde al hilo de sus lecturas había publicado algunos poemas y relatos que han sido rescatados del olvido (Cabezón, 1997). Aunque trabajó como contable en una serrería durante varias semanas de encierro y explotación, su propósito en la capital era ganarse la vida como escritor, al igual que Paco, el protagonista de una novela basada en experiencias concretas e inmediatas del autor:

Se detuvo al llegar a la casilla Profesión [de la hoja de inscripción de viajeros]. En principio estuvo a punto de declarar poeta, pero instantáneamente reconoció que no era serio, por lo menos en los papeles oficiales. ¿Escritor? ¿Por qué no? Al fin y al cabo había publicado cosas en los periódicos. Bueno, en un periódico, y

5. La novela nunca se ha reeditado, pero me anuncia Rafael Azcona que está prevista una nueva edición en La Coruña a cargo de Ediciones del Viento. 
de provincias, como recalcaba siempre Adolfo. Pero era lo mismo. Además, ¿qué otra cosa era él? Iba a trabajar en una oficina, sí, pero sólo porque de algo tenía que vivir mientras se daba a conocer (Azcona, 1958, 15).

No resultaba fácil darse a conocer en los ambientes literarios, «tener nombre», y aquellas veladas poéticas suponían una posible oportunidad pronto descubierta por Rafael Azcona, que dejó de acudir al Café Gijón de sus primeros días madrileños para trasladarse al Varela, donde «si no daban coronas de laurel, daban asiento y agua gratuitamente a todo sujeto capaz de subirse al tablado el viernes menos pensado para, desde la tarima, decir su 'triste' a través de un altavoz» (Azcona, 1956). Muchos años después, el autor declararía a su amigo Juan Cruz que «el Varela era mucho más acogedor que el Gijón» (Cruz, 1999, 37)6, aparte de contar con unos excelentes lavabos donde asearse cuando se carecía de domicilio propio o habitación compartida en una pensión. Asimismo, disponía de otros servicios no menos interesantes para quienes pasaban allí buena parte de la jornada. También le resultaban agradables otros cafés como el Comercial, donde ya avanzados los años cincuenta Rafael Azcona coincidió con Antonio Mingote, Ignacio Aldecoa, los hermanos Fernández Santos, Rafael Sánchez Ferlosio y otros buenos amigos alejados de las tertulias del Gijón. Quizá porque el local del Paseo de Recoletos se había convertido «en algo parecido a la Custodia de Toledo el día del Corpus. Digo en cuanto a objeto si no de culto, sí de exposición» (ibid., 41).

Rafael Azcona escribió la novela Los ilusos cuando llevaba casi siete años en Madrid. Apareció publicada en la editorial Arión de su amigo Fernando $\mathrm{Baeza}^{7}$, poco antes de contemplar por primera vez su nombre como guionista en la pantalla gracias a la llamada de Marco Ferreri a la redacción de La Codorniz (Azcona, 1990) ${ }^{8}$. La edición se incluyó en la colección «La tortuga perezosa», una de las más notables dentro de la prolífica

6. Rafael Azcona completa la justificación del traslado en su declaración a Marcos Ordóñez: «...emigré al Café Varela, que era el Gijón del pobre y tenía unos lavabos estupendos» (2007, 71). Tanto era así que hasta contaban con un otorrino que pasaba consulta allí mismo, en un tiempo que, como le sucediera al propio Rafael Azcona, era posible encontrar en plena Gran Vía un sastre que te tomara medidas y te hiciera un abrigo a pagar en razonables plazos.

7. Rafael Azcona nos explica que «Después de El pisito Ferreri hace Los chicos, película en la que yo no intervengo, y como estoy libre acepto la invitación de Fernando Baeza, que me pide un libro para 'La tortuga perezosa', una colección de humor de su editorial, y así escribo y publico Los ilusos» (Harguindey, 1998, 71). La redactó entre noviembre y diciembre de 1957.

8. Estudio la trayectoria literaria de Rafael Azcona, anterior a sus primeros trabajos como guionista en colaboración con Marco Ferreri, en Ríos Carratalá (2005). La mayoría de aquellas novelas han sido reescritas por el autor y publicadas en fechas recientes, con la llamativa excepción de Los ilusos. 
narrativa humorística de la época. Contó, además, con una portada y unas excelentes ilustraciones de Antonio Mingote, que captó con su habitual gracia unos personajes y un ambiente que conocía de primera mano. Sin embargo, y a diferencia de algunos títulos anteriores de la obra narrativa de quien colaboraba en la citada revista, en esta ocasión el humor sólo supone un componente más en una historia sacada de la observación de lo vivido y lo observado, de ese espectáculo cotidiano que siempre ha alimentado las creaciones de Rafael Azcona'. Ya en la solapa del libro se advierte del cambio al lector: «Azcona parece haber abandonado el comodín del chiste y del disparate y orientarse hacia una realidad sensible donde la situación, además de divertirnos, nos lleva a la reflexión y al entendimiento -no siempre y forzosamente risueños». Añade el anónimo redactor que esta nueva orientación sorprenderá a quienes le seguían: «tanto por su gracejo como por su verismo, de la misma manera que aquellas obras de nuestra picaresca clásica que están en la memoria de todos». La lectura de la novela, en esta ocasión, corrobora en buena medida lo anunciado por la editorial.

Rafael Azcona recrea en Los ilusos algunas de las experiencias vividas u observadas durante los seis meses que permaneció en un ambiente entre bohemio y picaresco, poblado por supervivientes aferrados a una esperanza o refugiados en los cafés de un Madrid hosco, donde las veladas poéticas constituían un auténtico acontecimiento para sus protagonistas. El novelista las describe con una mezcla de ternura y distanciamiento que le permite mantener la lucidez sin perder la capacidad de asombro. Esos encuentros aparecen como parte de una época todavía cercana pero de la que, en 1957, se sentía lejos porque «Yo he abominado siempre de la bohemia, incluso cuando estuve en sus aledaños» (Harguindey,1998, 26 ${ }^{10}$ ). Rafael Azcona realiza esta labor sin caer en una amargura que habría sido falsa, puesto que, como afirma en la misma conversación de sobremesa con amigos, «Nunca me sentí ni deprimido ni triste ni siquiera pobre, que ya tiene mérito, sobre todo si te pasas un mes y medio sin comer con cuchara, a base de bocadillos o de pan a secas» (ibid., 23). En aquellas penosas circunstancias materiales, participar en las veladas poéticas del Varela suponía un aliciente para perse-

9. En una entrevista publicada en 1962, le preguntaron si le gustaría llevar al cine algunos temas de la picaresca del Siglo de Oro. Su respuesta fue: «Pues... sí. Ahora bien, a mí no me apetece demasiado enfrentarme con los fenómenos que no estén ahí, a la vuelta de la esquina. Pienso que me gustaría hacer en cine la picaresca de hoy» (Herrera, 1997, 14). Así también había actuado a la hora de escribir novelas como Los ilusos.

10. Rafael Azcona, en declaraciones a Marcos Ordóñez, corrobora: «La bohemia era un asco. Lo que yo quería era ganar algo de dinero cuanto antes y alquilar una habitación para mí solo, por muy simpáticas que fueran la criada enana y la cocinera calva» $(2007,73)$. Se refiere a dos de las mujeres que trabajaban en la pensión, un tanto tétrica, donde vivía por entonces. 
verar: «Si uno conseguía actuar en los recitales se le reconocía como poeta con derecho a ocupar una mesa sin la obligación de hacer gasto, e incluso a pedir una jarra de agua» (ibid., 21). Auténticas gollerías para los protagonistas de Los ilusos, «esos aspirantes a la gloria de las Letras y las Artes, que aguardan su hora -si ésta ha de sonar algún día- sentados en los divanes y acodados a los veladores de los últimos cafés finiseculares que a Madrid van quedándole», según se indica en la citada solapa de la edición.

Rafael Azcona narra las andanzas más singulares de aquellos ilusos refugiados en el café y nos aporta un excelente testimonio para revivir las veladas poéticas que tanto asombraron a Paco, el protagonista procedente de Pamplona y aspirante a escritor ${ }^{11}$ :

¿Qué extraordinario y animador espectáculo el que ofrecía la pasión de aquellas personas, de aquellos habitantes del mundo puro de la Poesía! Siempre había pensado que sólo el fútbol era capaz de arrastrar a las masas, y ahora descubría que los versos desataban en Madrid las mismas tormentas que el Osasuna en Pamplona $(1958,54)$.

La conclusión era obvia: «Lo cuentas en Pamplona y no se lo cree nadie. ¡Aquí sí que hay afición a la poesía!» (p. 50). Se trata de un espejismo del que Paco tardará unos meses en comprender sus claves y limitaciones. Mientras tanto, el aspirante a escritor se siente partícipe de un relativo entusiasmo compartido con otros jóvenes a la búsqueda de un futuro que no pasaría necesariamente por la literatura. Esta actitud se basaba en un contagio explicable en el espacio reducido del café. También resultaba imprescindible para afrontar una cotidianidad repleta de carencias y convertida en vulgar apenas se acababan los ecos de los versos.

De la mano de un protagonista con rasgos autobiográficos, Rafael Azcona nos presenta en Los ilusos una de esas veladas organizadas con tanto afán y desvelos por Arriaga, cuyos rasgos fundamentales coinciden con lo que sabemos del citado Eduardo Alonso. Paco lee en un periódico el anuncio del IV Recital del II Curso de Versos sabáticos. Acaba de renunciar a su trabajo en la carbonería, está desorientado en una ciudad que todavía desconoce y la novedad de poder compartir sus inquietudes poéticas le entusiasma:

11. Francisco Durán Ruiz, el protagonista de la novela, había nacido en Pamplona el 18 de noviembre de 1925; es decir, apenas unos meses antes que Rafael Azcona, quien caracteriza a su personaje con otras ligeras variantes con respecto a la experiencia real vivida por el autor. Bernardo Sánchez nos indica que «A Azcona le había pasado casi todo lo que pasa a Paco en Los ilusos y lo relata con un leve enmascaramiento» $(2006,74)$. 
La noticia era sensacional: aquella noche, a las once, se celebraría el IV Recital del II Curso de Versos sabáticos. Emocionado, releyó la convocatoria una y otra vez. ¿Dónde estará aquel café? ¡Qué claro quedaba ahora todo! ¿Acaso no era providencial? Dejo el trabajo que me estaba embruteciendo, compro un periódico y, ¡zas!, el destino, mi destino (p. 49).

Sin dudarlo un instante, Paco acude al café y observa con asombro el ambiente de un recital donde interviene la poetisa Alberta Álvarez en estado de preñez. Según el narrador, explicó en tres sonetos lo contenta que estaba «por ser una clepsidra, una clepsidra que contenía un agua dulce, viva, rumorosa y azul, manada de una fuente de bronce estremecido, llegada desde las altas cumbres de un amor hecho de cálida nieve, de oscura luz, de suaves huracanes» (p. 89). Tras esta demostración de sensibilidad femenina y cultivo del oxímoron, intervino Narciso Barranco, «nuevo en esta plaza», que resultó ser un tremendista digno de los apuntes carpetovetónicos de Camilo José Cela. Subido a la tarima, explicó en términos poéticos que «no quería morirse, porque morirse era condenarse a vivir encerrado en una caja de tierra; pero tampoco quería vivir, porque vivir era condenarse a una muerte producida por hirientes botellas rotas» (p. 89). La noche iba de dilemas imposibles y los demás poetas no consiguieron despejar dudas entre tantas figuras retóricas de manual. Ni siquiera aquella hermosa joven que, ruborizada y sin leer, dijo que estaba sola y que su única compañía era un río: «Un río azul en la noche, verde en la mañana y rojo al atardecer» (p. 55). Como el chorrito de la fuente proyectado por el médico de ;Bienvenido, Mr. Marsahll! (1955).

Arriaga no era el único responsable de estos «aquelarres poéticos»a los que fueron convocados individuos con más o menos sentido común junto con los inevitables tontilocos, según el recuerdo de Rafael Azcona. La responsabilidad de las reuniones de Juvencia, otro colectivo cuyos recitales se celebraban en el Café Suizo, cerca de Tirso de Molina, correspondía a «dos tipos extraordinarios»: Amancio Perales y Doroteo Fardiñas, «el uno funcionario de Correos y el otro jubilado de Hacienda». Según el narrador de Los ilusos, el primero mantenía una doble vida como creador. En público y subido a una tarima cultivaba la poesía épica. La sonoridad de sus versos daba aires de proclama a unos poemas donde «sólo había clarines, yelmos, bombardas, espadas, aceite hirviendo, murallas, arcabuzazos y ondear de banderas ahumadas por la pólvora, rasgadas por los combates, pero siempre triunfantes» (p. 100). Mientras tanto, Amancio Perales hacía uso de su discreción y reserva cuando, en privado, se esforzaba en escribir cuplés que merecieran la atención de un afamado músico. Era su faceta creadora nunca reconocida, aunque encontrara 
justificación en la parquedad del salario. Ante los amigos o subido en una tarima, Perales prefería obviar una mácula incompatible con su espíritu épico y patriótico.

El funcionario de Correos no estaba solo en estos menesteres de la escritura mercenaria con aires sicalípticos. Rafael Azcona nos presenta en Los ilusos a Villena, otro sujeto que come y viste gracias a que una compañía de revistas pone en escena una obra suya. Pronto se quiebra «el huevo de la envidia» entre los puristas del café:

-Villena es un imbécil.

-Villena es un canalla.

-Villena... ¡Ojalá quemen el teatro!

- ¡Villena! Se le tenía que caer la cara de vergüenza. ¡Poeta, poeta, y su engendro se titula Benjamín es un pillín! (pp. 170-171).

Sin embargo, también se desata la alegría de sus contertulios y amigos que ven resueltas así sus tardes en el relativo confort de las butacas del Teatro Calderón. Arriaga, Mateíto, Fermín y Paco disfrutan durante una temporada de espléndidas vistas y estimulantes compañías mientras las vicetiples ensayan con voluntad. Nunca había que dejar pasar una oportunidad porque nadie les aseguraba que hubiera otra.

El otro responsable de Juvencia, el jubilado Doroteo Fardiñas, también llevaba a cuestas su cruz. Fiel a la tradición literaria por razones de edad y respetable condición de funcionario, escribía teatro en prosa: «producía lenta y trabajosamente todo lo que ya había producido en sus tiempos Echegaray. No se trataba de plagios, sino de coincidencias» (p. 101). Supongo que, por su mayor cercanía temporal, se podría encontrar algo de Eduardo Marquina en las fuentes nunca reveladas. Ya en el otoño de la vida, nadie osaba recordárselo y el bueno de Doroteo empleaba su tiempo libre en transmitir la vocación poética a quienes, semana tras semana, se reunían en las veladas de Juvencia, que suponemos similares a las de otros grupos o locales. Mantenían ideales...

A diferencia del Camilo José Cela que nos presenta poetas y tertulianos de parecidas características en algunos de sus apuntes de los años cuarenta y cincuenta, Rafael Azcona nunca se ceba en estos personajes mediante la impasibilidad del distanciamiento ni el recargamiento de lo grotesco. Hay ironía y humor en sus retratos, cierta tendencia a una justificada caricatura, pero sin perder el equilibrio necesario para reírse con sus criaturas, nunca de ellas. Al fin y al cabo, él también había participado de estos ambientes $\mathrm{y}$, como ha demostrado en decenas de guiones cinematográficos, ninguna debilidad humana le resulta completamente ajena. 
Este respeto a los personajes es compatible con una opinión crítica acerca del tipo de poesía que solía protagonizar las veladas de aquellos cafés de los años cincuenta. Paco, el protagonista, «ya había superado su inicial lorquismo» $\mathrm{y}$ «navegaba a aquellas alturas por el océano de la poesía social» (p. 28). Su llegada a Madrid le abre los ojos a nuevos temas para sus poemas, como el que piensa dedicar al tranviario, «el hombre que llevaba de un lado para otro a aquella humanidad paciente, sufrida, resignada...» (p. 28). Fracasa en el empeño por culpa de la rima y sin terminar de percibir, hasta mucho después, que él no se sentía poeta, como tampoco era un bohemio ni un pícaro capaz de tocar fondo sin desfallecer en su aspiración a sobrevivir. Paco se distrae con sus versos, como se entretiene en compañía de unos colegas de veladas siempre culminadas con mejores intenciones que realidades literarias. Aquel disparatado optimista que hablaba de doscientos poetas reunidos se había confundido. En realidad, eran doscientas personas agrupadas al calor de un local que les servía de refugio: «...pobres gentes cobijadas en aquella cueva que era el café, fugitivos de la dureza del mundo» (p. 121), como indica el narrador. Paco ni los enjuicia desde la perspectiva de su superado lorquismo, ni menos desde la de una poesía social cuyos verdaderos artífices andaban por otros derroteros. Aquella gente del Varela necesitaba compartir un calor indiferente a las cuestiones estilísticas y protagonizaba un fenómeno más social que literario.

Paco no sólo se encuentra con poetas líricos en las mesas del café donde tantas horas pasa cada día. Coincide también con el sensible y reflexivo Fermín, autor de novelas populares como las cuatro que escribió por entonces el propio Rafael Azcona bajo el seudónimo de Jack O'Relly. Los parámetros de esta literatura de kiosco estaban claros para quienes buscaban el sustento con la Remington alquilada: relatos de unos cien folios con mucho diálogo y párrafos cortos, redactados entre diez y quince días sin desmayos o dudas, firma con seudónimo en inglés y unas mil quinientas o dos mil pesetas como pago, siempre que no fuera la primera entrega y las anteriores hubieran funcionado bien en un mercado editorial por entonces pujante. Novelas del Oeste, de temática sentimental o rosa, policíacas, de aventuras en países exóticos... fueron redactadas en aquellos cafés con máquinas de escribir compartidas entre varios contertulios. Era una forma de supervivencia nada desdeñable para unos aspirantes a escritor, pero de escaso recorrido porque el mercado se saturaba pronto y, en buena medida, ya estaba copado por algunos especialistas como José Mallorquí, cuya productividad resultó tan legendaria como su popularidad.

El protagonista de Los ilusos poco a poco se da cuenta de que la materia para su novela la tiene alrededor, en la vida que descubre en el café 
poblado por «personajes variopintos, extraños y disparatados» (p. 62). Este microcosmos le atrae como observador nada distante, involucrado en una cotidianidad entre picaresca y absurda donde reinan tipos como Mateíto, «que no había pagado nunca ni un terrón de azúcar en el café» (p. 120) y termina de actor cómico en una compañía de revistas. Gracias a la capacidad de descripción de Rafael Azcona y las ilustraciones de Antonio Mingote, podemos disfrutar con su desparpajo para cultivar el arte del sablazo y su arrolladora gordura. Mateíto siempre anda metido en mil peripecias a la búsqueda de algo provechoso mientras se hace perdonar. Paco se siente atraído por su animoso amigo ${ }^{12}$, que se muestra incansable a la hora de maquinar nuevas argucias para un sustento limitado y efímero, como corresponde a la tradición picaresca. No obstante, también le vemos en calzoncillos, o los harapos que quedan de una prenda interior cuya integridad suponía un lujo inalcanzable para Mateíto. Es la otra cara de una tragicomedia donde Rafael Azcona encuentra el marco adecuado para una literatura y un cine inspirado en la vida alrededor. Lo demuestra en Los ilusos, cuyo protagonista lamenta que «en una novela rosa no se pudieran contar aquellas cosas» (p. 95). Tampoco en una película de género, de las basadas exclusivamente en la ficción del propio cine, que jamás han interesado a nuestro guionista. Y con algo de ironía nada complaciente por parte del narrador, añade que escribir una de las otras novelas «era lo mismo que tocar el violón: en España todo estaba copado por unos cuantos y era inútil intentar la lucha. ¡Qué país! Ni servía el talento, ni servía nada que no fuera la recomendacioncita, el enchufito, la arbitrariedad». Al menos, también servía un encargo como el de Fernando Baeza, un editor y correligionario de Dionisio Ridruejo que apostó por una novela capaz de mostrarnos una imagen del Madrid pobretón y grisáceo de los años cincuenta.

Paco podría haber seguido refugiado en aquellos cafés con veladas poéticas cada semana, a la espera de una oportunidad para abrirse hueco, entre otros ilusos que van agostando sus esperanzas. Pero, al igual que el propio Rafael Azcona, ya no se sentía poeta y, ni mucho menos, poeta maldito. La inevitable dispersión del grupo de amigos que había conocido tras su llegada a Madrid, la deserción de algunos de ellos porque contraen obligaciones laborales o familiares, el agotamiento que produce una penu-

12. «Paco seguía siendo dichoso con aquellas cosas: el desparpajo de Mateíto, que no había pagado nunca ni un terrón de azúcar en el café, le maravillaba y le enardecía, ayudándole a salir de los fosos en que le sumía algunas tardes la desesperanza» (p. 120). El desparpajo sin límites, su ímpetu y su gordura nos recuerdan al Vicente Bola de Tranvía a la Malvarrosa, de Manuel Vicent, que fue adaptada al cine por el propio Rafael Azcona y José Luis García Sánchez. Tal vez ambos novelistas y amigos hayan charlado en alguna ocasión de las personas que dieron origen a Mateíto y Vicente. 
ria crónica y radical... acaban minando la resistencia del joven venido de provincias para ganarse la vida como escritor. Su amigo Fermín, un correlato del Carlos Clarimón con quien Rafael Azcona compartió algunas de aquellas experiencias, argumenta la necesidad de salir de una vida tan falsa como carente de futuro:

No queremos aceptar la vida como es y nos obstinamos en embellecerla a través de un sueño estúpido. ¿Por qué estamos en el café, en ese limbo que es el café? Porque el café cae fuera del mundo. Allí nos masturbamos nuestra capacidad de ilusión, soñando una vida brillante, triunfal en todos los sentidos, limpia de torpezas y de inconvenientes; una vida en la cual todo sea hermoso, desde las mujeres hasta las piedras, desde nuestras alegrías hasta nuestros dolores; una vida falsa, en suma (p. 167).

Paco y Fermín se han quedado prácticamente solos y han tocado fondo en todos los sentidos. Se impone preparar el final de la novela mediante una llamada puesta en boca del mismo amigo:

Un día u otro tendremos que despertar, reconocer y admitir que somos unos imbéciles; volver con las orejas gachas a la única vida verdadera que existe: esa que nos rodea en la calle, esa que tiene sus inconvenientes, pero también sus ventajas, aunque sean pequeñitas (p. 167).

Cabe, pues, tomar una decisión, cambiar el rumbo vital para dejar atrás el limbo del café, divertido y singular, aunque con el riesgo de convertirse en un lastre. La alternativa puede ser tan demoledora como el futuro del que terminan huyendo ambos amigos:

Lo malo es que como sigamos aquí mucho tiempo nos vamos a quedar sin ilusión, nos vamos a convertir en unos hombres usados, inservibles, y ya no podremos, aunque lo queramos, volver a la realidad: a comer judías junto a un tipo repugnante, a enamorarnos de mujeres corrientes y molientes, a ganarnos la vida, la vida vulgar y acaso también mezquina, pero auténtica y única, con un trabajo honrado. Anda, anda, entra... Mira, mira a nuestros colegas. ¿Es o no es un limbo este café? (p. 167).

Rafael Azcona finalizó aquella etapa de bohemia al entrar a trabajar en la residencia Waldorf como persona para todo, hasta que pudo empezar a ganarse la vida como escritor. Su protagonista también hace caso a estas reflexiones algo retóricas y sigue el mismo camino en un hotel. Ambos dejan atrás una etapa agridulce de sus vidas. Dura y hasta desagradable en 
ocasiones por las carencias materiales, pero con ilusiones y divertida por el contacto cotidiano con una realidad disparatada donde convivían tipos cuya singularidad nos resulta atractiva. Al fondo de la historia, nos queda la imagen de unas veladas poéticas donde siempre había un tipo como Somorrostro capaz de emular al mismísimo Federico García Sanchiz -el célebre hablista de la época-, una poetisa preñada y un rapsoda entre paradójico y tremendista. También otros autores con más sentido común que no pasaron de las buenas intenciones. Todos juntos ni siquiera suponen una nota a pie de página en las historias de la lírica española, pero compartieron un calor humano con otros ilusos en unos tiempos donde resultaba imprescindible. La alternativa era la soledad, menos poética si cabe porque las casas o las pensiones estaban frías. 


\section{BIBLIOGRAFÍA CITADA:}

Alonso, Eduardo, Tickets de café, Prólogo de Manuel Mur Oti. Epílogo de César González Ruano. Ilustraciones de José Ejarque, Madrid, Imp. Luis Pérez, 1948.

Azcona, Rafael, Mi vidorra como escritor, Prólogo a Cuando el toro se llama Felipe, Tetuán, Ed. Cremades, 1956.

- Los ilusos, Portada e ilustraciones de Antonio Mingote, Madrid, Ediciones Arión, 1958.

— «Una llamada a La Codorniz», en Esteve RIAMBAU (ed.), Antes del Apocalipsis. El cine de Marco Ferreri, Madrid, Cátedra, 1990, pp. 33-37.

Bardem, Juan Antonio, Calle Mayor, Madrid, Alma Plot, 1993.

CABezón, Luis Alberto (coord.), Rafael Azcona, con perdón, Logroño, Instituto de Estudios Riojanos, 1999.

Cela, Camilo J., «Unos juegos florales», Obra completa, III, Barcelona, Destino, 1965, pp. 180-184.

Cruz, Juan, El peso de la fama, Madrid, Aguilar, 1999.

Frugone, Juan Carlos, Rafael Azcona: atrapados por la vida, Valladolid, Seminci, 1987.

Hardinguey, Ángel S., Rafael Azcona y Manuel Vicent, Memorias de sobremesa, Madrid, El País-Aguilar, 1998.

Herrera, Benito (ed.), Rafael Azcona, guionista, Cádiz, XXIX Muestra Cinematográfica del Atlántico, 1997.

OrdóÑEz, Marcos, Ronda del Gijón. Una época de la historia de España, Madrid, Aguilar, 2007.

Rimbau, Esteve y Casimiro Torreiro, «Entrevista a Rafael Azcona», Nosferatu, 33, 2000, pp. 4-28.

Ríos Carratalé, Juan A., Intoducción a Rafael Azcona, El pisito. Novela de amor e inquilinato, Madrid, Cátedra, 2005.

SÁnchez, Bernardo, Rafael Azcona: hablar el guión, Madrid, Cátedra, 2006.

Vicent, Manuel, Tranvía a la Malvarrosa, Madrid, Alfaguara, 1994. 